\title{
Past and Recent Conceptualisations of Sociomateriality and its Features: Review
}

\author{
By Aleksandra Bavdaz*
}

\begin{abstract}
This paper reviews the theoretical evolution of sociomateriality focusing on both the material and social, whilst considering the practical underpinnings. As part of the exploration, it is necessary to develop a definitional understanding of the term technology as it has been presented in many ways and by many scholars and scientists without clear alignment and agreement. One of the definitions for example describes technology as "computing", not providing any additional explanation, features or characteristics around the term, which indicated that prior literature underestimated either the technological or social world in practice. The evolution of definitions has led to a perspective of treating material and social as coexistent, avowed as sociomateriality. This paper presents how different views on sociomateriality have stimulated new understandings and new theoretical perspectives. In reviewing sociomateriality with a historical and critical note, the paper builds on relevant philosophical and ontological groundings, such as performativity and relational ontology, in contrast to this tackling ontology of separateness, which is considered not acceptable under any condition. The theorising of relational ontology led to the formation of "strong sociomateriality" presented as: "Matter is always as such in relation to what it materializes" (Martine and Cooren 2016: 148). Important to note is that the contrasting definitions were the ones presenting imbrication on one hand and entanglement of the two worlds on the other. This review presents the portrayal, purposes, treatment and usage of the phenomenon and its features by scholars. In the paper further practical examples of sociomateriality are explored whilst acknowledging the lack of examples in marketing focused on practice and as a result an emergent gap between material and social, which this paper addresses. In sum the aim of the paper is to present a shift in the perspectives of sociomateriality, alongside with an acknowledgement of materiality and sociality in practice and to develop stronger theories and concepts.
\end{abstract}

Keywords: Ontology of separateness, Practice, Relational ontology, Sociomateriality, Technology.

\section{Introduction}

Building on definitions of technology through years and many scholars' views, perspectives and thinking provided, have given birth to debates about technology-in-use (Orlikowski et al. 1995), sociomateriality with its groundings (Orlikowski 2009, Orlikowski and Scott 2008a, 2015), sociomaterial approach and most recent - third view on the phenomenon (Martine and Cooren 2016). The paper is divided in four themes: technology as part of sociomateriality, metatheories, features and the third view on sociomateriality.

\footnotetext{
${ }^{*}$ Researcher, University of Glasgow, UK.
} 
Definitional evolvement of technology that was from the very beginning in at least some connection to organisation, slowly led to debates about entanglement (Orlikowski 2009), imbrication (Leonardi 2011), intertwinement, inseparability, enactment and others showing relationality between two entities - materiality and sociality in practice (Orlikowski 2000, 2007, 2009, 2010, Orlikowski and Scott 2008a, 2015).

Discussions have as well been on philosophical grounds, moreover, ontological and epistemological assumptions, that still make scholars wonder whether sociomateriality posseses features of separability within the inseparable phenomenon - sociomaterial imbrication (Leonardi 2011) or entities joining together with no pre-existing relata (Barad 2003, 2007) forming constitutive entanglement, assuming inherent inseparability (Orlikowski 2010), however, looking beyond that, still leaving space for separability of agencies (Kautz and Jensen 2013, Martine and Cooren 2016).

On the very way of leading to breakthrough contributions, first, new streams under one umbrella of relational ontology emerged - STS, ANT, feminist studies and sociomaterial approach and second, scholars were building new theory with adding new notions, such as artefact (Leonardi and Barley 2008), apparatus (Barad 2003), affordance (Leonardi 2011), constrain (Leonardi 2011), object, entity, which were named as "sort-of" material agency. Given the latter, Barad (2007) has been working drawing upon agential realism, claiming that agencies emerge through intra-action - relations, but are quickly separated again within sociomaterial phenomenon, which she calls agential cuts that actually allows for separation of agencies for analysis of them. Assemblages are something that is again in contrast with inseparability, moreover, allowing for pre-existent relata and therefore a gap (Martine and Cooren 2016).

Wishing to ease off the tension and confusion about separability and inseparability of the agencies, new, the so called third perspective on sociomateriality emerges in a recent study (Martine and Cooren 2016) that underpins it with dividing already existent perspectives on weak (Leonardi 2011, 2012) and strong (Orlikowski 2009, Orlikowski and Scott 2015) sociomateriality and presenting every single thing as to have both material and social compartment (Martine and Cooren 2016).

\section{Technology as Part of Sociomateriality}

As many as there is papers that many there is definitions of "technology". Some claim technology is hardware or software, others say that speaking only about technology is too simplistic since it ignores social reality and once put in a social context it starts having its real meaning and purpose (Suchman 2007), some say that term technology could be too focused as being a "special case" rather than to be seen as a part of almost every piece of organisation (Orlikowski 2007). In this thematic chapter I am aiming to present the evolvement of the term technology that slowly has led to material (technology) and social (routines, humans, organisations) become related, imbricated, enacted, entangled and many 
more as under debates in recent studies (Martine and Cooren 2016, Kautz and Jensen 2013, Orlikowski 2015, Cecez-Kecmanovic 2016).

At this point it is good to note that technology has been, at least to a little extent, since the very beginning somehow connected to organisation or described within organisational context (Orlikowski 1992). With the new technology in workplace sociomateriality as a concept emerged and became "trendy" (Leonardi 2011).

In organisational studies it can be noted many ongoing debates on how to posit technology within an organisation (Orlikowski 1992). I can notice technology in practice was not at all treated as inseparable in the relation to human - social, but was rather described as "an understanding of how technology interacts with organisations" (Orlikowski 1992: 398). This thematical chapter is divided on sub-themes as follows: organisational studies and organisational theory, technology in use and more recent views on technology, that means views presented from year 2000, regardless of the new perspective on sociomateriality (Martine and Cooren 2016).

\section{Organisational Studies and Definitional Development of Technology}

Speaking of organisational studies in which this paper is rooted in, I want to give a clear definition of organisational theory, which is the following: organisational theory is a theory that consists of various approaches that aim to analyse organisation (structures, relationships, link with their external environment, various behaviours and such). It includes modernization, bureaucratic theory, contingency theory, division of labour and such (Business Jargons 2017). Moreover, it most importantly includes contingency theory that draws upon dependency, claiming there is no best way to organise a company, because that depends on its internal and external situation (Business Jargons 2017).

The oldest evidence from the studied literature goes back to linking technology to industrial production (Woodward, 1958), followed by the so called "social technology" (Perrow 1967, Thompson 1967), following on to arguing that discussions could go beyond the notion hardware (Mintzberg 1979) and lastly to virtual technology in practice - or better virtual communication (Orlikowski 2010, Gaskin et al. 2010, Faulkner and Runde 2010).

It was suggested that technology was an independent variable, affecting dependent work, organisation process and other variables in an organisation (Perrow 1960). Moreover, for many years technology was seen as only being part of the organisational process (Perrow 1960). First generation of research that was carried out in order to prove effects of technology on organization's structure, such as the level of hierarchy, degree of centralisation etc. that lead to another generation of research (Perrow 1960). The latter was mainly focused on how technological change impacted work of an individual in an organisation, such as its accomplishment, organization process and other processes in an organisation (Perrow 1960). The researchers of that time relatively quickly came to the conclusion that unpredicted changes and shifts were what was the 
result of technology impacting organizational structure and its processes (Perrow 1960).

Many researchers of that time were trying to theorize the relationship between technology and organisation in many ways, however, theories on the mentioned were mostly very general in order to take under umbrella different types of technology and different types of organisations (Mohr 1982). All that [generalising] led to the emerging of contingency theory (Jiang et al. 2006), which purpose was to look at various contingencies influencing technology's impact within the organisational context. Machinery for instance was not only included in the factory, but as well in the offices as a substitution for human labour (Blauer 1976), which can be called remote control (Bailey et al. 2012).

The more the term technology and its definitions evolved the more was becoming clear that social was connected with materiality and vice versa in almost all cases, for best outcome entities could be even forming relations.

Some definitions on technology described technology as "industrial production technique" (Woodward 1958) (Orlikowski 1992: 399). In some cases technology was defined as simply as "computing" (Attewell and Rule 1984, Orlikowski and Scott, 2008b) and focused on either technology or organisation on the expense of one or another, which can be called technological (Lucas 1975) or social determinism (Attewell and Rule 1984, Barley 1988, Davis and Taylor 1986, Hartman et al. 1986, Scott 1981, Orlikowski 1992). Generalisability was present as well, speaking of using the term "hardware" for overall description of technology (Barley 1988, Blauer 1976, Orlikowski 1992). Noticeably, technology started to be given more importance on relation with sociality or social with calling it "social technologies", presenting human engagement in technological activities (Eveland 1986, Perrow 1967, Orlikowski 1992).

Developing definitional understanding of technology further, another idea of technology was proposed (Barley 1988) that drew upon Winner's (1977) three explanation for the term technology: 1. machines and devices, 2. technique, including behaviours and cognitions and 3. organization, being a combination of technological tools, people and tasks. The last two of explanations of technology were criticised as being confusing, what is more understanding technology within the organisational context and treating technology and humans as one would be without much sense (Barley 1988). Regardless of the critique Barley (1988) suggested technology to be described with the notion "social object", furthermore, this notion being limited to include objects and actions only. Moving further, the focus shifted to the introduction of "advanced information technology" (Huber 1990), describing it with having basic (processing capacity, storage capacity) and advanced characteristics (less expensive, more precise and accurate, more information access) (Orlikowski and Scott 2008b).

Definitions of technology until the 1980s and 1990s were mostly rooted in positivistic research manner (Orlikowski 1992). The extreme philosophical perspective being described as follows: the observer is external to reality, there is only one, single reality that is measured, positivist uses hypotheses and deductive approach to theory, uses generalising and statistical probability and 
sampling includes and requires large numbers, which are selected at a random basis (Saunders and Bristow 2015, Easterby-Smith et al. 2012, Crotty 1998).

\section{Technology-in-use}

The development in thinking and debating on technology brought about the need for deeper understanding of technology within the organisation context, moreover, to start understanding technologies and humans interaction with each other (Orlikowski 1995). That further on led to understanding the latter mentioned entities as entangled, intertwined and enacted in practice and relationality (Orlikowski and Scott 2009, 2015), not mentioning the contrasting imbrication (Leonardi 2011, 2013), agential realism (Barad 2007), agential cuts (Barad 2007) and such.

It was when technology was implemented in organizational, occupational and institutional forces that it started to be variously used in work practice and therefore started to be called "technology-in-use" (Orlikowski 1995) or "sociotechnology-ensembles" (Bijker 1995, Orlikowski and Scott 2008a).

Structuration model of technology picked up from Giddens (1984) was presented (Orlikowski 1992) in relation to technology in practice that in contrast to positivistic approach started introducing interpretive views. The latter will be better described under metatheories of sociomateriality later on (CecezKecmanovic 2016). At this point of time Orlikowski (1992) argued for "duality of technology", that means for the technology to be understood as with two roles - as the outcome and medium for human action (Orlikowski and Scott 2008a).

Shifting on, 7 theories of technology, built upon Collins, Hage and Hull's (1986) definition were introduced (Roberts and Grabowski 1996). Moreover, they included aspects of mechanical systems (e.g. hardware), human component (e.g. networks, skills, energy) and knowledge systems (e.g. concepts, understandings) (Orlikowski and Scott 2008a). Progressing in time and academic debates on technology in practice, technology was described as "Information systems and information technologies"-"IS and IT", including the following features divided into two groups: 1. efficient, effective, rational, economic, time saving and 2. having the ability to pool resources and therefore create collaboration across roles (Orlikowski and Scott 2008a).

\section{More Recent Views on Technology}

More recent studies suggest that technology is a combination of material artefacts and social impact in a socially recognizable format, such as software and hardware (Orlikowski 2000). Even though the interest in international technology management is becoming of more and more interest to researchers it was not always like that. Moreover, there is an observation that suggests that technology in connection with MNC's (multinationals) management had not always been in the centre stage of the research (Brouthers et al. 2002, Leonardi 2008). Some other more recent studies show that by explaining what technology 
is, how it works, why does it work in a certain way and such, international managers put material into social context (Leonardi 2008). Furthermore, performing the latter causes changes of which some can be predicted in advance, while other are unanticipated (Leonardi 2008).

Last, but not least, the view on term technology was placed within the concept of contemporary information technology - greater capacity of communication, integration, computing power and such that create various opportunities to focus and organise around processes, rather than separate steps or functions (Zammuto et al. 2007). Definitional development went further describing technology as "a broad concept that deals with a species' usage and knowledge of tools and crafts." and "referred to material objects of use to humanity, such as machines, hardware or utensils, but can also encompass broader themes, including systems, methods of organisation and techniques" (Orlikowski and Scott 2008a).

Term technology was developed through years, debated by many authors, their words given "birth" sociomateriality as we know it from more recent debates. The reason why sociomateriality was born lies in the recognition that within the workplace social affects material and vice versa, what is more it was recognised that materiality is materiality because it was created through social processes and social is social because of materiality (Leonardi 2012). Moreover, a variety of information technologies were introduced to organisation and therefore social and material coming together needed some definitonal grounding - sociomateriality (Huber 1990). Described in the one of the following subchapters I revised many papers and collected many authors' views in order to provide for a detailed evolvement of sociomateriality. But first metatheories of sociomateriality.

\section{Metatheories of the Sociomateriality Phenomenon}

Metatheory aims at giving a systematic description of sociological theory, as well as at providing some predictions for the future of these social theories (What-when-how.com 2017). Moreover, metatheory is "a theory devised to analyse a theory" or "the investigation and analysis of theories" (Dictionary. com 2017).

This thematic chapter will by critically engaging with all the mentioned reveal the definitional evolvement of philosophical assumptions and perspectives, shifting first from positivist paradigm to social constructivist paradigm and then to relational ontology and sociomaterial approach (Cecez-Kezmanovic 2016). Throughout this evolvement, ontology of separateness, dualism, entanglement, inseparability, relationality, assemblage, ANT, STS, causality and some other notions are tackled as well as part of development. 


\section{Ontological Grounding of Sociomateriality}

In order to clarify the term, I decided to provide a short description of ontology, which will be given a lot of attention in the following paragraphs. Ontology is a study about things - entities that exist in the universe that particularly in information technology studies deals with relations, things and events that are specified in some way in order to create an outcome (Larose 2005).

\section{Streams and Perspectives on Technology}

Presenting research streams - I, II and III and perspectives - absent presence, exogenous and entanglement perspective to this subchapter is aimed at better understanding of new technology, as it gives better understanding of how perspectives developed and what changes happened on the way and in which areas (Orlikowski 2010).

New technology is by definition "Technology that radically alters the way something is produced or performed, especially by labour-saving automation or computerization; an instance of such technology" (Oxford Dictionaries 2017f).

First, there are two research streams - I and II (Orlikowski 2009) and second, there are two different perspectives - absent presence and exogenous perspective, that all contributed and impacted the emergence of the stream III and the entanglement perspective (Orlikowski 2010).

\section{Research Streams I, II and III}

Research stream I considers material and social as entities that influence each other, that is treating technology as important when there is an occurrence of an occasion. For example, when an organisation adopts new technology, materiality is point of attention to specific groups of people within the organisation that deals with it. (Orlikowski and Scott, 2009). While research stream II puts interactions of social and material on the centre stage (Orlikowski and Scott 2009). As a result of both streams, stream III emerged, which focuses on agencies that are entangled together or with other words so "saturated in each other that before taken for granted boundaries are dissolved" (Orlikowski and Scott 2009: 455). A shift from ensembles to shifting assemblages happens, where the first means separate entities of technology and people before joining together and the second people and technology joining together, without pre-existent boundaries, where boundaries are formed (materialization) through relations (Orlikowski and Scott, 2009). This is called constitutive entanglement, within relational ontology that presumes "inherent inseparability" of social and material worlds and which will be further discussed in the later debate (Orlikowski and Scott 2009).

Other than streams of technological research, there are three different perspectives on viewing technology in management studies, the first two, as I 
mention above, bringing about the perspective three (Orlikowski 2010). The latter shifted ontological view on sociomateriality from ontology of separateness to relational ontology (Orlikowski 2010).

\section{Perspectives on Technology in Practice}

The first of three perspectives is absent presence perspective that talks about materiality of everyday organising, which was missing from the literature, was black-boxed or reduced (Orlikowski 2010, Latour 1992, Faulkner and Runde 2010). According to that perspective matter (materiality) was not acknowledged enough in studies of organisational reality, that is practice (Barad 2003, Orlikowski 2010).

Secondly, another perspective on technology is exogenous force that suggests technology to be rather autonomous (and external force) in the context of management studies (Orlikowski 2010). Moreover, it suggests that impacts of technology within organisation can be predicted, change happens in relation to humans, outcomes, structures, routines, decision making, performance and such within an organisation (Orlikowski 2010). Exogenous perspective can be attuned to positivist paradigm that was, according to statistical data provded in the paper (Cecez-Kecemanovic 2016) mostly adopted as an approach to research in 1980s and 1990s and which is presented in the process of changing from positivist IT/IS research to interpretivist IT/IS research (Cecez-Kecemanovic 2016). Moreover, positivist paradigm is, as subject to many criticism and thinking, related to technological determinism, describing it as "one-dimensional causal relationship among IS/IT cases and their effects" (Cecez-Kecemanovic 2016: 45). Scholars adopting positivisticly oriented exogenous approach were very much interested in developing generalizable laws and theories from statistical work (Orlikowski 2010), which is what Orlikowski's past practical examples are critiqued upon - MPK20 example, which introduces common features of synthetic worlds that are described and studied in order to provide general explanation (Orlikowski 2010). Overall, positivism tends to only assume that there is one, single reality (McLean and Aroles 2016).

\section{Structuration Model of Technology}

Orlikowski (1992) had drawn upon Giddens theory (1984), who started presenting interpretive approach in dominantly positivist research in 1980s and 1990s and presented "structuration model of technology" (Cecez-Kezmanovic 2016: 45). The model gave new insights and opened up new opportunities for IT/IS understanding and thinking with allowing for both subjective and objective treatment of social reality. The structuration theory was about a good balance between the human subjectivity and the objectivity of knowledge - with the purpose to overcome on one extreme objectivism's focusing on detached structures, without focusing on human as well and extreme subjectivism that focuses on people only, without considering socio-structural context (CecezKecemanovic 2016: 47) and was as such used by many authors in order to 
develop thinking on organisational activities (Barley 1986, Smith 1983, Riley 1983) (Orlikowski, 1992). The model belongs to social theory and allows for understanding of the engagement of humans in technology - in their use and development, all in the relation and dependence on context, human agents and technology (Cecez-Kecemanovic 2016: 46). One important feature of structuration theory is that it presumes technology to be absolutely dependent on human agency in terms of its use and affordance (Orlikowski 1992). However, the model is not suggested to be used in any empirical research, as it was not meant to be a methodology and can therefore be problematic in this sense (Stones 2005).

Looking at the effect of Gidden's structuration theory on sociomateriality, I can argue that his theory had bad effects on it, which are as follows. It is believed that structure according to the latter stated started having less influence on technology, giving less importance to properties of material and giving less importance to the degree with which structural agents would be engraved in the mentioned properties (Cecez-Kezmanovic 2016). To clarify, structure is made of principles, rules and resources humans in practice follow in day to day activities and interactions (Orlikowski 1992).

The movement from positivist research thinking to constructivist research thinking happened, this is when, as could be seen from stream I and II and the first two perspectives (Orlikowski 2009, Orlikowski 2010), then the shift towards relational ontology and sociomaterial approach happened, which brought about thinking of entanglement of material and social and thinking of relations.

\section{Relational Ontology}

Relational ontology suggests that social (humans, routines) and material (digital, physical technologies) come to existence through forming relations and in practice, that means they are not pre-existent with their boundaries (CecezKecmanovic 2016). Relating that to entanglement, entities emerge through relations, what is more entanglement means "lacking an independent, self-contained existence" (Barad 2007: ix, Cecez-Kecmanovic 2016).

Scholars have been using working within the relational ontology that took the perspective that neither technical nor social can be prioritised, our existence with objects had become so much linked and entangled with each other that it is not possible to treat neither technology nor humans separately, however, each entity should be seen as one reality or highly entangled in practice (Orlikowski 2010).

Same as above Orlikowski and Scott (2009) argue that organisational practices are necessarily entangled with material, since they need to be performed through some material mean, such as mobile phone, computer, human bodies and other. Orlikowski bringing up the problem of ontology of separateness that sees material and social as two different realities (Faulkner and Runde 2010). Suchman (2007) in contrast to Orlikowski, states that technology and social should be viewed as two separate realities, meaning they are two different things (speaking of pre-existent boundaries of entities) that need to be joined together. Speaking of which, Orlikowski (2015) believes that there is pre- 
existing relations, which points at separateness between material and social, before they join and become inseparable, while Leonardi $(2011,2013)$ and Barad $(2003,2007)$ believe that ontology of separateness can be recognised within the phenomenon - agential cuts.

Knowing that relational ontology is the one seeing material and social inseparably rather than as two separate things, distinction between technologies and humans is not acceptable anyways and even if it exists in theory, the theory includes recognition that in practice technology and human will be in inseparable entanglement and claim that social and material do not have in separate features, but generate them through and with interpretation (Orlikowski and Scott, 2008b).

Within relational ontology Barad (2003) argues that we should see entities rather than independently, being inherently inseparable, with no pre-existing relation, where their features and boundaries become determinate only with forming relations with another entity and findings can be developed through the apparatus - material - discursive practice as she describes it (Orlikowski and Scott, 2009). Barad (2003) here points at performativity.

Under the movement that was influenced and inspired by relational ontology, there were several streams emerging at the same time, such as Actor-Network Theory (ANT), socio-technical systems (STS), science and feminist studies and after all sociomaterial approach that emerged within IS and social sciences, at the point of time when it was really hard to keep the distinction between technical, material and practice (Cecez-Kezmanovic 2016). Sociomaterial approach is very much based on Barad's agential realism (Cecez-Kezmanovic 2016) that presents the ontological inseparability of entities that emerge through intra-acting between agencies (Barad 2007). These entities are only given the existence if entangled in a relation with another entity within a phenomenon, however, being in separation through the so called "agential cuts" (Brad 2007).

\section{(Constitutive) Entanglement}

Constitutive entanglement is what more recent approaches - such as entanglement perspective, relational ontology and such, were striving towards (Orlikowski 2009, Orlikowski and Scott 2015). By more recent approaches I count approaches before the recent third perspective on sociomateriality, which might still have some of these views and perspectives. It actually pictures that material and social is not about what material is within social, but what constitutive effect does an agency (human or non-human) have within a network of social and material (Pels et al. 2002). Moreover, it assumes that there is no dual realities, in contrast to Orlikowski's previous claims for duality (Orlikowski 1992), such as material being separated from social and the understanding as well it moves from ontology of separateness perspective, meaning to go, as Barad (2003) argues, towards constitutive entanglement, that is no separate entities, such as material and social exist, nor they are with inherent features and characteristics (Orlikowski, 2007).

Entanglement, as defined in English Oxford dictionary is "the action or fact entangling or being entangled" or "a complicated or compromising 
relationship or situation" (Oxford Dictionaries 2017e) and is the main concept (beside constitutive inseparability) of sociomaterial phenomenon consisting of social and material, "two actors that continually co-construct reality and at the same time co-constitute each other" (Cecez-Kezmanovic 2016: 48).

The focus of MPK20, which is an example of Orlikowski (2010) once mentioned above, is on its understanding and is not necessarily a result of some technology or a reflection of humans work and thinking. Moreover, objects of synthetic world (such as MPK20) and its material agencies do from entanglement perspective, within relational ontology, not need to be directly attributable to individuals and/or particular technologies (computers, graphics etc.), but should rather be seen as relational (relational ontology), distributed and enacted (Orlikowski 2010).

Entanglement perspective does not want to focus on "impacts" or "usershumans", because this might cover the purpose of human and material agencies (Orlikowski 2010). Moreover, scholars will from the mentioned perspective see MPK20 material agency configuring communication, practices more saliently than others. Within entanglement perspective sociomateriality would see synthetic world materials (such as MPK20) as dynamic (rather fixed in time and practice) and being part of social and material.

\section{Agential Realism, Agential Cuts and Inta-acting}

Karen Barad is an American theorist, who is especially known for theorising and discussing agential realism, her research topics including physics, epistemology, ontology, cultural studies, feminist theory and such (Feministstu dies.ucsc.edu 2017).

As to Barad (2007) individuals (agencies) appear through the intra-action, which joins the agencies There is no actors that could intra-act with the phenomenon and would remain out of the performative outcome, that Barad (2007) calls "agential cuts" (Cecez-Kezmanovic 2016). Agential realism that is the main focus of Barad's thinking is at the same time ontological and epistemological framework (Barad 2007). Moreover, we can find "agential" and "realism" " in one same conceptualisation - agential realism, that lingers between realism and social constructivism academic debates (Cecez-Kezmanovic 2016). What is more, Barad (2007) talks about agencies as being enacted through the process of intra-acting and is by no means something that an entity has (Cecez-Kezmanovic 2016).

At this point I can clearly note that both Orlikowski and Leonardi in their debates draw upon Barad's perspectives on apparatuses being joined together. Orlikowski's perceptions are rooted in ontology, while Leonardi's thinking concerns epistemology - social constructivism, which I can relate to affordances or how individuals perceive materiality and agential cuts, which present separateness within the phenomenon. 


\section{Performativity}

Barad (2003) argues for performative perspective (performative metaphysics) that moves away from meanings, features and boundaries to practices that "perform particular phenomena" (Orlikowski, 2010: 136).

Orlikowski and Scott (2008a) paper addresses the idea that is inscribed in sociomateriality (and is known to be central in terms of the notion sociomateriality) - the notion of performativity (linked to enactment), which sheds the light on how technologies and humans' relations and boundaries are not defined ahead or pre-given, but are rather enacted in practice.

Callon (2006) states that "discourse may be said to be performative if it contributes to the constitution of the reality that it describes" (Orlikowski and Scott 2008: 460) - with its presence helps to create (like material and social being part of one whole).

\section{Actor-Network Theory (ANT)}

ANT was developed by Callon (1986) and Latour (1987) and it suggests that humans and technology do not only interact with each other, but are symmetrically relevant (Law 2004). Moreover, Law (2004) states that an object is a result of various relationships. From ANT perspective humans and technologies, that are inseparable, build a network with human and material agencies, that make a temporary alignment with human and technology, aiming at achieving particular effects. Kallinikos (2006) argues that technology - or technological information as he calls it - is an element or part of an institution and institutional life. Moreover, technological information is therefore crucial for reorganization of organizational reality in various ways, which I recognise as the latter leaning towards before and further on described Orlikowski's thinking.

ANT or Actor network theory that emerged as part of the stream under relational ontology, has been observed, defined and debated by many scholars, some even suggesting that it should adopt the Giddens approach that is as described before Giddens presenting structuration theory (McLean and Aroles 2016). However, authors of the observed paper agree that ANT tends to explore how assemblages come together, which are the entities, how they form and maintain the network, how the latter is controlled, performed and such.

\section{Socio-Technical System (STS)}

Socio-technical system is another term related to material and social that should be looked at within the context of materiality and social practice. It emerged under the movement that was influenced and inspired by relational ontology, along with several other streams emerging at the same time such as actor-network theory (ANT), feminist studies and after all sociomaterial approach that emerged within IS and social sciences (Cecez-Kezmanovic 2016). 
Leonardi (2012) presents socio-technical system as such that combines social (networks, knowledge, practices) and technology (machinery, systems, programmes) that actually represent one organisation's environment. Moreover, material features of technology can support human tasks and desires, dependant on what goals and ideas about its usage do humans have.

Relational ontology can be as well explained through the socio-technical system (Trist and Bamfort 1951, Griffith and Doughtery 2001) that sees technology as a part of a whole within one workplace, humans and environment (working), all shaping each other.

Between the Two Ontologies - Ontology of Separateness and Relational Ontology

As a result of Kautz and Jensen (2013) Jester dialogue, taking into account Orlikowski's, Orlikowski's and Scott's assumptions on one hand and Leonardi's assumptions on the other, there is one big question that appears: Can sociomateriality be understood within two ontologies at the same time? Here I talk about ontology of separateness and relational ontology. Explaining it further that means presenting sociomateriality as one phenomenon being derived from two contradictive philosophical assumptions.

Talking about entanglement as focused upon by Orlikowski and Scott (2008a, 2008b, 2009, 2015), which is rooted in relational ontology in contrast with imbrication presented by Leonardi (2011, 2013), Barad (2003, 2007), which is rooted in ontology of separateness (Kautz and Jensen 2013).

Orlikowski in her work ( 2009), alongside with Scott (2008, 2013, 2015) (Kautz and Jensen 2013) draws upon relational ontology and inseparability of social and technology, in many of her works using the so called entanglement one of the perspective called like that as well (Orlikowski and Scott, 2009). Noticably, entanglement itself does not allow for separation of entities, however, there is still separation beyond the term entanglement and other term Orlikowski uses - assemblage, relationality and performativity (Orlikowski 2007) that is described in the following lines.

As to Orlikowski and Scott (2009), Barad (2007) writes that humans are already automatically part of material. Same authors in a different paper identify sociomateriality as a term that make technology and social practice within organization inseparable (Orlikowski and Scott 2008b).

Sociomateriality seen through Orlikowski's and Scott's eyes makes the lines between social and material invisible since it focuses on agencies (human and non-human agency) that actually saturate each other rather than point out material and social interaction or /and influence. Moreover, it is not about entities (actors) interacting with each other, nor is it about actors influencing each other, however, social and material should be seen as saturated in one another and absolutely inseparable (Orlikowski and Scott 2008b). 
Vol. 5, No. $1 \quad$ Bavdaz: Past and Recent Conceptualisations of Sociomateriality ...

\section{"Imbrication" and "Entanglement"}

Again Leonardi on one hand uses the term "imbrication", using tiles and imbrex as an example to picture relation between human and material agency (Leonardi 2011, 2013). The latter clearly showing separation between the two agencies. Imbrication as a notion in context with sociomateriality tends to picture human and material agency as separate and distinct entities, however, still being interdependent, that means influencing each other (Leonardi 2011). On the other hand Orlikowski draws upon material and human (agencies) being intertwined in practice, while Leonardi in this case is using the term entwining. Intertwined meaning "twist or twine together or connect or link closely" (Oxford Dictionaries 2017a) and entwined meaning "wind or twist together" (Oxford Dictionaries 2017b). What I can see here, which confirms the above writing, is a vocabulary game of using two different terms that have very little differences in meaning for one same concept - sociomateriality.

Orlikowski and Scott (2009) present terms such as sociomaterial assemblages, relationality, performativity and constitutive entanglement, all of them again having a very similar meaning. Moreover, all the latter terms, especially assemblage, indicating a gap as addressed by Martine and Cooren (2016). The gap is about assemblages, relations and other consisting of pre-existing relata, which indicates separateness, that has as a consequence an inseparable phenomenon (Kautz and Jensen 2013). Again what I can see is separateness in inseparable phenomenon, with for instance assemblage meaning " a collection or gathering of things or people or a machine or object made of pieces fitted together or the action of gathering or fitting things together" (Oxford Dictionaries 2017c), where actors are not contained in each other, but allow for pre-existence of separate things - being made up of things (Kautz and Jensen 2013), which is contradictory to what Orlikowski (2009) claims in her papers - inherent inseparability of entities.

However, as well as Barad (2003) Leonardi (2011) considers sociomateriality as a phenomenon as inseparable. Moreover, he believes that material and human agencies "build an integrated structure through integration" (Leonardi 2011: 151). A big dilemma then appears: Can we say sociomaterial imbrication? After all this would mean mixing separateness and inseparability or mixing ontology of separateness and relational ontology. Barad (2003) does not necessarily mention the term sociomateriality in her studies, however, she believes in performativity and intra-activity inside one phenomenon (Kautz and Jensen 2013), which I can easily apply to material and human agencies.

According to Barad's (2003) writing technology does not have particular meanings, features or boundaries, however, it bounds up with certain practices (material-discursive practices, which Barad names apparatus) and actions and forms phenomena (Orlikowski 2010). What Barad (2003) is trying to point out is that features and boundaries of technology are not priorly talking about relational ontology, however, they only become determinate in the relation with apparatus (material-discursive practice) - results are seen through this materialdiscursive practice (Orlikowski 2010). 
To sum up it is not exactly clear, whether Orlikowski considers inseparability of entities - consequence of ontology, intertwinement and separateness through assemblages that in their mean consist of separate parts. On the other hand it is as well contradictive how Leonardi mixes separateness and inseparability, playing vocabulary games with terms imbrication - indicates separateness and entwining - means inseparability.

Not only Kautz and Jensen (2013), but also more recent studies (CezecKezmanovic 2016) claim that sociomaterial approach with its foundation in relational ontology, even though being given attention for more than a decade already, has been misunderstood and undervalued. Mutch (2013) in his paper argues that sociomateriality has taken a wrong turn with Orlikowski and Orlikowski and Scott leading it in the confusion of being caught between two ontologies, rather than picking one paradigm or one approach to it. However, as an answer, Orlikowski and Scott (2015) argue that because of various aspects and approaches to sociomateriality, the development in the IS / IT field has come very far, moreover, as to the same authors, no one says there has to be only one perspective to the phenomenon.

\section{Orlikowski}

Orlikowski has been by many scholars accused of not being clear enough with her positioning of sociomateriality, that is as well generalizing in examples too much (Kautz and Jensen 2013), which in my opinion can indicate gaps in the knowledge or theorising. Moreover, Orlikowski does according to scholars (Kautz and Jensen 2013) seem not to use clear and straightforward vocabulary, as well as she seems to not to indicate enough what sociomateriality means and what role does it play in relation to IT and IS (Kautz and Jensen 2013). Her theorizing of sociomateriality was as well called "jargon monoxide" (Sutton 2010) with an explanation of the notion not providing any clear expressions, language, what is more, even creating contradictions (Kautz and Jensen 2013). Orlikowski linging between performativity and social always being involved in material, creates some contradictive ideas and distraction between ontology of separateness on one hand and relational ontology on the other, while Leonardi is clear in thinking stating that there is always separateness inside the phenomenon - agential separateness (Kautz and Jensen 2013).

Wanda Orlikowski is specialised in organisational studies, theory and information systems. In her studies she is mostly focused on the fact that material and technology in workplace should be paid more attention to (Faulkner and Runde 2010). Orlikowski's research is mostly focused upon the relations between material and human or technology and organisations. She is known for drawing upon Gidden's (1984) structuration theory. 


\section{Leonardi}

Paul Leonardi is the Duca Family Professor of technology management at the University of California (UCSB's Technology Management Program 2017), apart from being a director of one of the investment groups. Leonardi's reaserch is mostly about how companies build their organisational network and implement and introduce new technologies within that network. Moreover, he is very keen on research on social media and other where new ways of presenting, storing and sharing information is the subject of attention (UCSB's Technology Management Program 2017).

The following Table 1 in a clear way presents the two contrasting ways of explaining inseparability between technology and humans/material and human agencies, separately from Orlikowski's and Leonardi's view tackling ontology, some notions, separateness vs. inseparability, literature, clarity, vocabulary, practical examples and other.

Table 1. Overview of Orlikowski and Scott and Leonardi Perception of Sociomateriality

\begin{tabular}{|l|l|l|}
\hline & \multicolumn{1}{|c|}{ Orlikowski } & \multicolumn{1}{|c|}{ Leonardi } \\
\hline Ontology & $\begin{array}{l}\text { Rooted in relational ontology with } \\
\text { separateness features }\end{array}$ & $\begin{array}{l}\text { Rooted in represational } \\
\text { ontology }\end{array}$ \\
\hline What is more & $\begin{array}{l}\text { Allowing pre-existent relata - } \\
\text { assemblage, relationality, } \\
\text { constitutive entanglement }\end{array}$ & $\begin{array}{l}\text { Allowing separateness of } \\
\text { agencies within the } \\
\text { phenomenon - imbrication }\end{array}$ \\
\hline $\begin{array}{l}\text { Separateness / } \\
\text { inseparability }\end{array}$ & $\begin{array}{l}\text { Inseparability of humans and } \\
\text { technology, indicates a gap - } \\
\text { separability beyond the above terms }\end{array}$ & $\begin{array}{l}\text { Separateness of agencies - that } \\
\text { is not about separating, but } \\
\text { rather analysing of what is } \\
\text { visible }\end{array}$ \\
\hline $\begin{array}{l}\text { Literature } \\
\text { drawn upon }\end{array}$ & Barad (2003, 2007) & Barad (2003, 2007) \\
\hline $\begin{array}{l}\text { Clarity of } \\
\text { language }\end{array}$ & $\begin{array}{l}\text { Unclear, jargon monoxide (Sutton, } \\
\text { 2010) }\end{array}$ & Clearer \\
\hline $\begin{array}{l}\text { Vocabulary } \\
\text { used }\end{array}$ & Intertwined & Entwined \\
\hline $\begin{array}{l}\text { Practical } \\
\text { examples }\end{array}$ & $\begin{array}{l}\text { IT in use - Google engine - } \\
\text { entities seen as a whole }\end{array}$ & $\begin{array}{l}\text { Automotive industry - entities } \\
\text { seen as separate }\end{array}$ \\
\hline Other & Pre-existing relata (Barad, 2003) & $\begin{array}{l}\text { No pre-existing relata, agential } \\
\text { cuts, intra-action (Barad, 2003) }\end{array}$ \\
\hline
\end{tabular}

\section{Features of Sociomateriality}

Driven by my objectives I organised features of sociomateriality as follows: material and human agency, affordances and constrains, artefacts, physical and digital materiality, Orlikowski's examples and presentational example. 


\section{Material and Human Agency}

Within the context of sociomateriality there are two other terms that occur - material agency and human agency, which both perform action, but each with different intention. Moreover, they both shape one's practice, but each in their own way (Leonardi 2012). In relation to agencies, there is materiality that brings about some confusion on definitions of material and their relation to digital technology that mostly appears as part of IT.

What is more, material agency tends to represent the functionality of technology in a workplace, while human agency represents the ability of an individual to set and realize their goals (Leonardi 2011). Moreover, material agency is never in complete control of itself, while human agency can control its actions all the time. "Exercising its actions through performativity" (Kautz and Jensen 2013: 21) material agency does things that cannot be directly controlled by humans, however, the latter still keeps the given status of a "head", while material agency is known to be "complement" to humans (Leonardi 2011). Both material and human agency have an effect on humans and their actions, however, as already said, material agency influences them in lesser proportion having a status of a "complement", while human agency in this same instance has the status of being a "head" (Kautz and Jensen 2013).

A confusion might appear on what is the difference between material agency and materiality. The distinction is suggested as follows: materiality means material features of an object, while material agency gives material the function that is independent of human (i.e. rain - raining) and his control (Leonardi 2012). Moreover, material features of an object will less likely change with place and time, while function can often change. On the other hand human agency is defined (Leonardi 2012) as one's ability to pursue their goals. Human agency means the practice of setting and carrying out one's goals. To make it clearer, humans contain human agency and technology contains material agency. Leonardi $(2011,2012)$ sits on the perspective that human and material agency within a phenomenon make intra-actions (Barad 2007), which means they are treated as a subject of separation within definitionally inseparable phenomenon - sociomateriality, this I can relate to the before discussed imbrication (Leonardi 2012).

\section{Affordances and Constrains of Materiality}

It can be argued that every materiality (material) possesses affordances and constrains that are dependent on an individual and context. Moreover, while materiality stays the same perceived affordances and constrains define the usefulness of material for an individual. In other words, perceiving materiality differently might or might not enable an individual to carry out his goals according to what he thinks material can or cannot do.

What is more, the thing in materiality that likely matters more than the matter is materiality's affordance (Leonardi 2011). The latter means that it is more important how humans perceive materiality than the humans to know 
what the thing is made out of (Leonardi 2011) and as James Gibson clearly stresses it is relative what an object, surface or people afford to a certain person, since every person is different and might see a different affordance in one same material, which as well means various outcomes (Leonardi, 2011).

The statement that well presents the above written is the following: "Language matters. Discourse matters. Culture matters. But there is an important sense in which the only thing that does not seem to matter anymore is matter" (Barad 2003: 801).

Before I mentioned affordances either being affected by people, who recognise them or people's perceptions of materiality being affected by materiality's affordance. However, it is not that straight forward, as affordances and people form a relationship (relational ontology) when coming in contact (Hutchby 2001, Leonardi 2011). With other words, human agency that represents human goals approach the affordance that represents material agency and together they form a relationship (Leonardi 2011). Again this leads me to intraacting within the phenomenon. It is important to note that materiality should include both tangible and intangible artefacts, because this is the only way we can say that material properties stay the same, while affordances change across various contexts, because people, who approach them have different human agency - goals (Hutchby 2001, Leonardi 2011).

\section{$\operatorname{Artefact}(s)$}

Another notion appears within the context of materiality, this is artefact, which is by definition a technological object, made up of material features and other symbol features, presented in some form, such as software, hardware and other (Leonardi and Barley 2008). However, a dilemma here appears. When speaking of information technology, most of it is non-material - intangible, which should still be recognised as material, because it has got all the material features same as hard, tangible materiality (Leonardi 2011, Kautz and Jensen 2013: 22).

Leonardi in his papers present artefacts, alongside with objects, apparatuses (Barad 2003), which he introduces as sort of material agencies (Martine and Cooren 2016).

Affordances are said to be the properties of artefacts (Norman 1990, 1999), so they show the user what they can do and how useful is that thing to the users (Leonardi 2011), which underpins the above statement about artefacts by Martine and Cooren (2016). On the other hand users are important to materiality, because they recognize the affordance, however, they do not play any role in establishing it, thus, affordances are created by designers of materiality (Leonardi 2011). 


\section{Materiality - Physical and Digital}

It should be noted that materiality is not the only thing that defines technology, it is materiality - digital and/or physical and form of it that come together and result in what we call the right technological outcome available to the users at all times (Leonardi 2012).

Term "materiality" is used and described in relation to technology in order to describe it through its physical and digital features in a way that makes it (technology) available to everyone at the same time (Leonardi 2012). One must be aware of the fact that materiality does not necessarily mean physical. Moreover, taking an example of a screw driver and a software programme we can see that it is easy to identify materials in a physical technology such as the screw driver, compared to a totally intangible - digital software programme. One can easily see that most digital technologies have no physical materiality, some digital will however, be accessible through certain technology that have got physical features such as keyboard and monitor. However, the latter will have no impact or will in no way change the non-physical (digital) technology (Leonardi 2012).

Being aware of what Leonardi (2012) states, firstly, Orlikowski (2007) claims that materiality in practice has been treated in a very broad way, taken for granted and very much downplayed, rather than understood through various arrangements, infrastructures and such through which practices and organising are performed. And secondly, if opposed to that, materiality in the literature has been seen as specific cases of technology implemented and used within organisations, which disables a general view of materiality within the organisational papers and research (Orlikowski 2007).

It can be argued that materiality means "fixed" and "stable", moreover, something that does not change drastically with place or/and time. However, Orlikowski (2000) argues that technology is nothing but changeable and it evolves with time and place. An example of changeable technology could be Microsoft Excel that is being updated very regularly in a modern era. Moreover, this means that its materiality is being changed rather than staying fixed with time and place shifts (Leonardi 2012). However, in between Microsoft Excel versions, it materiality in it remains stable, which enables people to work on the same document/database and share it with each other.

Given the assumption that materiality is made of hard, tangible properties only, it would be very hard to count digital technology that is intangible in that group. Looking up definitions of the term "material" three explanations are proposed (Leonardi 2012): 1.physical substance - matter; 2. practical instantiation and 3.significance.

Materiality, as technology in practice has been tackled by many scholars in the fields such as sociology, management and communication studies (Leonardi 2012). Orlikowski through her examples as well indicates that materiality does not necessarily have matter to be called that. The latter is presented in the Google engine example. 
Orlikowski's examples to show entanglement, agencies, materiality and social working in practice. Orlikowski provides a number of examples picturing the entanglement of material and social. Amongst a variety, I decided to pick one and describe it into detail. This is an example of Blackberry from Orlikowski's paper from 2007.

\section{Google Engine}

Firstly, Orlikowski (2007) provides a great example of Google engine with its page ranking system. People look up certain things on the internet, using Google search engine mostly. What is more, Google is the only engine that enables millions of websites to be listed in order according to ranking. And for everything functioning as assumed there need to be thousands of back-up people, who take care that the whole system works as it should, that if something goes wrong they fix it immediately and so on. It can be clearly noted that architecture of Google consists of various databases, servers, indexes, algorithms and much more as stated by Orlikowski (2007). What is more, entanglement perspective with its constitutive entanglement shows very clearly in this example, especially with non-fixed and sociomaterial results: the order at which pages are ranked is dynamic and is a result of entanglement of material and social (humans). Moreover, the whole google engine is dynamic, relational and contingent, meaning that they are not related neither on material nor social only, nor do ther interact with each other (Orlikowski 2007). Constitutional entanglement resulting in mangling of material and human agencies is what Suchman (2007) calls "a creative sociomaterial assemblage" (Orlikowski 2007).

What makes Google search engine even more dynamic in time and place is the fact that same or different people searching at different times will bring up different results, same as searching for same results in different places (e.g. China and the U.S.) will due to various restrictions and bans give different results as well (called as the productive consequence of the sociomaterial assemblage). In fact, the stated in this paragraph is called multiplicity - "that which takes different shapes in different places" (Law and Urry 2005, Orlikowski 2007). Moreover, given the construct of sociomateriality, engines such as Google will shift and change regarding to political, institutional conditions, by time and by location.

\section{$\underline{\text { BlackBerry }}$}

The sociomaterial stance in example of Blackberry implementation in Plymouth organisation shows how company had created a network of human agency, material agency, materiality within the social context in order to benefit. Moreover, since Blackberry at that time enabled anyone at any time to receive an email (if there was wi-fi), which resulted in 24/7 entanglement of employees with the device - new technology in practice. As cited in the paper (Orlikowski 2007), one of the employees says that once you see a notification you do not hesitate to answer right away, because you know it is so easy and it takes little amount of time. Moreover, you are also more than aware that everybody will 
know that you have seen the message and you are for that reason pressured to give answer in a certain amount of time. The latter written is right what the purpose of Plymouth headquarters was - to provide an environment that will "force" employees to be connected with the firm at all times in order to keep everybody stay in touch basically 24 hours a day every day. It can be argued that in the case of Plymouth company and the implementation of Blackberry in their working practice it is not about material interacting with social (employees) and vice versa or material impacting social and vice versa, but it is about how new technology becomes entangled with and within social context (it actually becomes part of employees business as well as private life and line between the two became blurred, which undermines family-friendly values of the company) (Orlikowski 2007).

The Difference between Materiality, Material Agency, Human Agency and Social Practice Presented Through the Example

Let's take an example of Microsoft Excel to picture the difference between materiality, material agency, human agency and social practice. Microsoft excel with its material features offers quite some options (this is what material is) for one to carry out his or her goals. However, someone using these features shifts the perspective to what material does (material agency - function of material), which is in the eyes of a human very much dependant on what constrains and affordances he or she sees in the technology according to his formation and realization of goals. However, human's affordances and constrain do not change the material features or functions in any way, but might see them differently with his or her eyes.

\section{The New - Third View on Sociomateriality}

No matter the vocabulary, such as "entanglement" (Orlikowski 2009, Orlikowski and Scott 2008b), that makes it hard for separation, the distinction between material and social (Kautz and Jensen 2013, Cecez-Kezmanovic 2014) can still be identified (Martine and Cooren 2016). The main aim of the paper I draw upon in this subchapter (Martine and Cooren 2016) is to look beyond relational ontology in order to fill the gaps of separateness between entities. Including other authors and relevant papers (Kautz and Jensen 2013, CecezKezmanovic 2014, Leonardi 2012, Leonardi 2011, Orlikowski and Scott, 2008 I open up a debate that shows new perspectives and new lens to sociomateriality, while discussing the "weak versions" of the phenomenon (Martine and Cooren 2016).

In the past 10 years in the literature there is a turn, the so called "material" turn have started to change perspective on sociomateriality (Martine and Cooren 2016). The latter turn concerns division on weak and strong sociomateriality (Martine and Cooren 2016). 


\section{Beyond Imbrication and Entanglement there is a Gap}

Regarding the weaker version, there is Leonardi (2011, 2012), who presents agencies and sheds light on materiality not having a proper meaning if not part of social and vice versa (Martine and Cooren 2016). What is more, artefacts, apparatuses (Barad 2003), technology, objects and such is what Leonardi in his papers presents as a sort of material agency (Martine and Cooren 2016). Leonardi as well denies separation, however, two agencies intra-acting within the phenomenon (Barad 2003, 2007) shows nothing else, but separation (Martine and Cooren 2016). With imbrication, Leonardi (2013) belongs to the weak programme of sociomateriality (Martine and Cooren 2016), while Orlikowski belongs to the strong programme of sociomateriality, alongside with Scott and Barad. The latter scholars stand for constitutive entanglement of meaning and matter, where there is no separateness between agencies, what is more ontologically material and social are inherently inseparable, which is an important evidence that speaks for the strong side (Martine and Cooren 2016: 145). Moreover, properties of entities are formed when relating to each other, that is when formation of relations happens, deriving from that these relations can be broken down into more and more relations, which seems to overcome Leonardi's separateness between agencies. The whole point of entanglement is to show that materiality is not fixed, but flexible and dynamic (Martine and Cooren 2016).

It can be argued that entanglement avoids separation of social and material, which can be misleading, because of such vocabulary as twisted/bound/ entangled that does not take into account how the two entities - human and material agency become inseparable and what is more, takes that for granted (Martine and Cooren 2016).

\section{The Third View on Sociomateriality}

All the different definitions that I present throughout this paper have led to redefining of the notion sociomateriality, bringing about the third - new perspective (Martine and Cooren, 2016). The latter perspective presents every single thing, even something intangible, such as an idea or a routine, needs materia (latin) - something it is made of - in order to have the ability to exist to materialize itself (Martine and Cooren 2016).

"Matter is always as such in relation to what it materializes" (Martine and Cooren 2016: 147). Driven by this saying, an organisation consists of customers, reputation, employees and such, taking as an example a manager, who through her talking to partner materialises organisation, the manager is at the same time in relation to other organisation's features. Noticeably, features that materialise organisation are relational, however, at the same time they materialise themselves through relations (Martine and Cooren 2016). That pictures the inseparability or incapability of social and material existing separately, since relation needs material property to materialise through (such as a manager that performs a discourse) and every materiality needs to relate to other materiality for the 
outcome to happen (discourse) (Martine and Cooren 2016). In this context the word through is very important, because it represents the inseparability, which enables the concept to overcome the gap where separateness still exists no matter the notions entanglement and imbrication (Orlikowski 2009, Leonardi 2011).

\section{The Conversation between Jester and the Queen - Orlikowski/King - Leonardi}

Krautz and Jensen (2013) paper is one I am really keen on and have as well drawn upon in terms of sociomateriality evolvement. This paper starts addressing the gap between material and social by leading conversation between jester and the queen/king. Jester represents honesty and common sense and is in the paper addressing important questions in order to create a discourse to shed a light on particular, not yet explained dilemmas. Queen presents the views based on Orlikowski and Scott (2008b) and Orlikowski (2007, 2009), while king represents the views based on Leonardi and Barley (2008) and Leonardi (2011). Here we are looking at two yet contradictive views on sociomateriality. Moreover, Orlikowski's relational ontology not really being completely inseparable and Leonardi's sociomateriality accepting separateness of the two agencies. I think that the way authors present and points out concepts and missing explanations leads to an important contribution for a better understanding of the sociomateriality development process.

Ontological distinction in both queen's and king's perspectives on the phenomenon is still present, even though not noticeable at the first stance and no matter the use of terms such as entanglement, intertwined, being bound together, where bound means closely related or connected to (Oxford Dictionaries 2017d), it still allows for ontological distinction. Thinking of Orlikowski and Scott (2008b), Kautz and Jensen (2013) are with their suspicions leading to breakthrough contributions in terms of development of socio-material aspects and perspectives, indicating suspicion about how can material and social be seen separately for analytical purposes and not epistemological - ontology? That already indicates that relational ontology does not stand for complete inseparability, however, there is a gap. Moreover, same authors agree that notions entanglement, assemblage, mutual constitution and even relationality are not showing inseparability, which can be considered with looking beyond the latter notions, thus driven by human tendency of separating things.

By engaging critically with before described ideas, Kautz and Jensen (2013) provoke questions, such as: "How to give materiality a voice through narrative?", "How to let the thought of material and social being treated as separate when analysing, however, when speaking of relational ontology inherently inseparable?" The latter questions open up new dilemmas and options for further debates.

Building on indications from almost ten years ago, when Orlikowski and Scott $(2008 \mathrm{~b})$ presented the idea of material and social worlds to be related through relational ontology, knowing that the distinction between the two is not acceptable under any circumstance, Martine and Cooren (2016) present a stronger 
socio-material concept, which fills the gap between material and social as mentioned above.

\section{Conclusions}

The paper introduced, first, many aspects on technology, that with the implementation of computers and other technology in organisation led to the birth of sociomateriality and second, metatheories, features and new perspective on the phenomenon. New ideas and perspectives opened up new debates and enabled me to critically think and evaluate. Moreover, as well some questions emerged that will be a good starting point for further research, such as: Since Orlikowski provides very general examples, does this point at positivistic assumptions? Can new perspective on sociomateriality as well have a gap? Is there separateness within the new perspective?

\section{References}

Attewell P, Rule J (1984) Computing and organisations: What we know and what we don't know. Communications of the ACM 27(12): 1184-1192.

Bailey DE, Leonardi PM, Barley SR (2012) The lure of virtual. Organisation Science. Articles in Advance: 1-20.

Barad K (2003) Posthumanist performativity: toward an understanding of how matter comes to matter. Signs 28(3): 801-831.

Barad K (2007) Meeting the Universe Halfway: Quantum Physics and the Entanglement of Matter and Meaning. Duke University Press, Durham.

Barley SR (1988) Technology as an occasional for structuring: Evidence from observation of CT scanners and the social order of radiology departments. Administrative Science Quarterly 31: 78-701.

Beunza D, Hardie I, MacKenzie D (2006) A price is a social thing: Towards a material sociology of arbitrage. Organization Studies 27(5): 721-745.

Bijker WE (1995) Of Bicycles, Bakelites, and Bulbs: Toward a Theory of Sociotechnical Change. Cambridge, Massachusetts: The MIT Press.

Blauer M (1976) U.S. Patent No. 3,973,275. Washington, DC: U.S. Patent and Trademark Office.

Saunders M, Bristow A (2015) Research methods for business students (Chapter 4) Understanding research philosophy and approaches to theory development, 122161.

Brouthers KD, Brouthers LE, Werner S (2002) Industrial sector, perceived environmental uncertainty and entry mode strategy. Journal of Business Research 55(6): 495-507.

Business Jargons (2017) What is Organizational Theory? Definition and meaning Business Jargons. Retrieved from http://bit.ly/2g7Ev2b [Accessed 7 August 2017].

Callon M (1986) The sociology of an actor-network: the case of the electric vehicle. In M Callon, J Law, A Rip (Eds), Mapping the dynamics of science and technology, 19-34. London: Macmilian Press.

Callon M (2006) What does it mean to say that economics is performative? HAL: 1-58.

Cecez-Kecmanovic D (2016) From substantialist to process metaphysics - Exploring shifts in IS research. UNSW Business School, 35-57. 
Collins PD, Hage J, Hull F (1986) A framework for analysing technical systems in complex organisations. Research in the Sociology of Organisations 6: 81-100.

Crotty M (1998) The foundations of social research. Crows Nest, Australia: Allen \& Unwin.

Davis FD, Taylor JC (1986) Technology, organisation and job structure. In R Dublin (Ed). Handbook of work, organisation and society, 379-419. Chicago, IL. Rand McNally.

Dictionary.com (2017) The definition of metatheory. Retrieved from http://bit.ly/2g7 EVph. [Accessed 7 August 2017].

Easterby-Smith M, Jackson PR, Thrope R (2015) Management and business research, Chapter 1-3. Seven oaks. Sage publications.

Eveland JD (1986) Diffusion, technology, transfer and implementation. Knowledge, creation, diffusion, utilisation 8(2): 303-322.

Faulkner P, Runde J (2010) Technological objects, social positions and the transformational model of social activity. MIS Quarterly 37(3), 803-818.

Feministstudies.ucsc.edu (2017) Karen Barad. Retrieved from http://bit.ly/2w0vAVA. [Accessed 7 August 2017].

Gaskin J, Schutz, D, Berente N, Lyytinen K, Yoo Y (2010) The DNA of design work: Physical and digital materiality in project-based design organizations. International conference on Information systems.

Giddens A (1984) The constitution of society: Outline of the theory of structuration. Los Angeles: University of California Press.

Griffith TL, Dougherty DJ (2001) Beyond socio-technical systems: introduction to the special issue. Journal of Engineering and Technology Management 18(3): 207-218.

Hartmann HI, Kraut RE, Tilly LA (1986) Computer, chips and paper clips: Effects of technological change. Washington, D.C.: National academy press.

Huber GP (1990) A theory of the effects of advanced information technologies on organisational design intelligence and decision making. Academy of Management Review 15(1): 47-71.

Hutchby I (2001) Technologies, texts and affordances. Sociology 35(2): 441-456.

Kallinikos J (2006) Information out of information: On the self-referential dynamics of information growth. Information Technology and People 19(1): 98-115.

Kautz K, Jensen B (2013) Sociomateriality at the royal court of IS: a jester's monologue. Inf. Organ. 23(15-27).

Jiang JJ, Klein G, Chen H-G (2006) The effects of user partnering and user nonsupport on project performance. Journal of the Association for Information Systems 7(2): 68-90.

Larose DT (2005) Discovering Knowledge in Data: An Introduction to Data Mining. New Jersey: Wiley.

Latour B (1987) Science in action: how to follow scientists and engineers through society. Cambridge: Harvard University Press.

Latour B (1992) Where are the Missing Masses? Sociology of a Few Mundane Artefacts. In E Wiebe Bijker, J Law (Eds), Shaping Technology/Building Society: Studies in Sociotechnical Change, 225-258. Cambridge, Mass.: MIT Press.

Law J, Urry J (2005) Enacting the social. Econ.Soc. 33: 390-410.

Law J (2004) After method: Mess in social science research. London: Routledge.

Leonardi MP, Barley SR (2008) Materiality and change: Challenges to build better theory about technology and organizing. Information and Organization 18(3).

Leonardi PM (2011) When flexible routines meet flexible technology: Affordances, constraint and the imbrication of human and material agencies. MIS Quartely 35(1): 147-167. 
Leonardi PM (2012) Materiality, sociomateriality and socio-technical systems: What do these terms mean? How are they related? Do we need them? In PM Leonardi, BA Nardi, J Kallinikos (Eds) Materiality and Organizing: Social Interaction in a Technological World, 25-48. Oxford: Oxford University Press.

Leonardi PM (2013) Theoretical foundations for the study of sociomateriality. Information and Organisation 23(2): 59-76.

Lucas, HC, JR (1975). Performance and the use of an information system. Management Science 20: 908-919.

Martine T, Cooren F (2016) A relational approach to materiality and organising: The case of a creative idea. Beyond interpretivism? New encounters with technology and organisation. IFIP WG 8.2 Working Conference on Information Systems and Organizations, IS\&O 2016, Dublin, Ireland, December 9-10, 2016, Proceedings

McLean C, Aroles J (2016) Rethinking stability and change in the study of prganisational routines: Difference and reputation in a newspaper-printing theory. Organisation Science 27(3): 535-550.

Mintzberg H (1979) An emerging strategy of direct research. Administrative Science Quarterly 24(4): 582-589.

Mohr LB (1982) Explaining organisational behaviour. Jossy-Bass Social and Behavioural Sciences. San Francisco.

Mutch A (2013) Sociomateriality: taking the wrong turning? Inf. Organ. 23(1): 28-40.

Orlikowski JW (2000) Using technology and constituting services: A practice lens for studying technology in organizations. Organization science. 11(4). p. 404-428.

Orlikowski JW (2007) Sociomaterial practices: Exploring technology at work. Organization Studies 28(9): 1435-1448.

Orlikowski WJ, Scott SV (2008a) The entangling of technology and work in organisations. Information systems and innovation - Department of Management.

Orlikowski WJ (2009) The sociomateriality of organisational life: considering technology in management research. Cambridge Journal of Economics 34: 125-141.

Orlikowski, WJ (2010) The sociomateriality of organisational life: considering technology in management research. Cambridge Journal of Economics 34(1): 125-141.

Orlikowski WJ (2000) Using technology and constituting structures: A practice lens for studying technology in organisations. Organisational Science 11(4): 404-428.

Orlikowski WJ, Scott SV (2008b) Sociomateriality: Challenging the separation of technology, work and organisation. The Academy of Management Annals 2(1): 433-474.

Orlikowski WJ et al. (1995) Shaping electronic communication: The metastructuring of technology in the context of use. Organisation Science 6(4): 423-444.

Orlikowski WJ (1992) Duality of technology: rethinking the concept of technology in organisations. Organ. Science 3(3): 398-427.

Orlikowski WJ (2009) Sociomateriality: Challenging the separation of technology, work and organisation. The Academy of management annals 2(1): 433-474.

Orlikowski WJ, Scott SV (2015) Exploring material-discursive practices. J. Manage. Stud. 52: 697-705.

Oxford Dictionaries (2017a) Intertwine - definition of intertwine in English. Retrieved from http://bit.ly/2xuWhQf. [Accessed 7 August 2017].

Oxford Dictionaries (2017b) Entwine - definition of entwine. Retrieved from http://bit. ly/2w04RZc. [Accessed 7 August 2017].

Oxford Dictionaries (2017c) Assemblage - definition of assemblage. Retrieved from http://bit.ly/2wAmyjy. [Accessed 7 August 2017].

Oxford Dictionaries (2017d) Bound - definition of bound. Retrieved from http://bit.ly/ 2vrakEZ. [Accessed 7 August 2017]. 
Oxford Dictionaries (2017e) Entanglement - definition of entanglement. Retrieved from http://bit.ly/2xv4a8n. [Accessed 7 August 2017].

Oxford Dictionaries (2017f) New technology - definition of new technology. Retrieved from http://bit.ly/2vrr5ji. [Accessed 7 August 2017].

Pels D, Hetherington K, Vandenberghe F (2002) The status of the object performances, mediations, and techniques. Theory, Culture \& Society 19(5-6): 1-21.

Perrow C (1967) A framework for the comparative analysis of organisations. American Sociological Review 32(2): 194-208.

Perrow P (1960) Authority, goals and prestige in a general hospital. Unpublished $\mathrm{Ph} . \mathrm{D}$. dissertation, University of California, Berkeley.

Riley P (1983) A structurationist account of political culture. Administrative Science Quarterly 28: 347-414.

Robers K, Grabowski M (1996) Organisations, technology and structuring. In S Clegg, S Hard, W Nord, Handbook of organisational studies, 409-423. London: Sage publications.

Scott WR (1981) Organisations: Rational, Natural and open systems. Englewood cliffs. NJ. Prentice Hall.

Smith CW (1983) A case of study of structuration: The pure-bred beef business. Journal for the Theory of Social Behaviour 13: 3-18.

Stones R (2005) Structuration theory. New York, NY: Palgrave Macmillan.

Suchman LA (2007) Human-Machine reconfigurations: Plans and situated actions. UK Cmbridge: University press.

Sutton RI (2010) Sociomateriality: More academic jargon monoxide.

Thompson JD (1967) Organisations in action. Transaction publishers. London: New Brunscwick.

Trist EL, Bamforth KW (1951) Some social and psychological consequences of the Longwall Method of coal-getting: An examination of the psychological situation and defences of a work group in relation to the social structure and technological content of the work system. Human Relations 4(1): 3-38.

UCSB's Technology Management Program (2017) Home. Retrieved from http://bit. ly/2v8t1Cf. [Accessed 7 August 2017].

What-when-how.com (2017) Metatheory. Retrieved from http://bit.ly/2g7LrfI. [Accessed 7 August 2017].

Winner L (1977) Autonomous technology: Technics out of control as a theme in political though. Cambridge, MA: MIT Press.

Woodward J (1958) Management and technology. London: HMSO.

Zammuto RF, Griffith TL, Majchhrazak A, Dougherty DJ, Faraj S (2007) Information technology and the changing fabric of organisation. Organ. Sci. 18(5): 749-762. 
